\title{
Investigación científica forense mediante técnicas de coloración en casos de delito sexual
}

Forensic scientific research using coloration techniques in cases of sexual offense

Joseline Lizbeth Frías García ${ }^{1}$, Verónica Paulina Cáceres Manzano ${ }^{2}$, Adriana Monserrath Monge Moreno ${ }^{3} \&$ Patricia Jenny Lescano Fonseca ${ }^{4}$

\begin{abstract}
.
DOI: https://doi.org/10.33262/cienciadigital.v3i1.1.361

Within the Forensic Area, the spermatozoon tracking contributes to the investigation of a Sexual Offense constituting as a complementary / confirmatory test in case of positive findings, which later appear as evidence before a trial, through expert reports. In our investigation, we wanted to try an alternative staining technique that contributes to the Forensic stains thus contributing to the Investigative Sciences in cases of Crime or a sexual assault allowing the proper investigation of the act in search of its authors. For this reason, when comparing the Eosin and Christmas Tree technique in the spermatozoid tracing, and applying the protocols known for them, we find advantages and disadvantages in microscopic observation that directly affect the quality of visualization and differentiation of the Parts of sperm cells, but with great success for the positive finding in the determination of the presence or absence of spermatozoa in the samples analyzed.
\end{abstract}

Keywords: Forensic, staining, screening, spermatozoon

\section{Resumen.}

\footnotetext{
${ }^{1}$ Universidad Nacional de Chimborazo, joselinefriasgarcia@gmail.com

${ }^{2}$ Universidad Nacional de Chimborazo, vcaceres@unach.edu.ec

${ }^{3}$ Universidad Nacional de Chimborazo, amonge@unach.edu.ec

${ }^{4}$ Servicio Nacional de Medina Legal y Ciencias Forenses, lescanopatrick@ gmail.com
} 
Dentro del Área Forense el rastreo de espermatozoides contribuye a la investigación de un Delito Sexual constituyéndose como una prueba complementaria / confirmatoria en caso de hallazgos positivos, que posterior se presentan como evidencia ante un juicio, mediante informes periciales. En nuestra investigación quisimos probar una técnica de tinción alternativa, que contribuya a las tinciones Forenses aportando de esta manera a las Ciencias Investigativas en casos de Delito o una agresión sexual permitiendo la investigación adecuada del acto en busca de sus autores. Es por ello que al comparar la técnica de Eosina y Christmas Tree en el rastreo de espermatozoides, y aplicando los protocolos conocidos para las mismas, hallamos ventajas y desventajas en la observación microscópica que afectan de forma directa a la calidad de visualización y diferenciación de las partes de las células espermáticas, pero con gran éxito para el hallazgo positivo en la determinación de presencia o ausencia de espermatozoides en las muestras analizadas.

Palabras claves: Forense, tinción, rastreo, espermatozoide.

\section{Introducción.}

Se define a las ciencias forenses como el conjunto de varias ciencias, técnicas y métodos que se aplican con el fin de buscar la verdad y a los autores de un delito, mediante el análisis de indicios, manejados en el marco legal. Hoy en día gracias a los esfuerzo por garantizar una justicia transparente, el Ecuador cuenta con una red de 8 Centro de Investigación de Ciencias Forenses (CICF) que cuentan con diversas áreas para el proceso pericial en los diferentes delitos a tratar, así como el área de Biología Forense. (Fiscalía, 2013)

La Biología forense es la rama de las ciencias forenses encargada del análisis científico de indicios biológicos, de una escena del crimen sean esta de homicidio, femicidio, delito sexual u otros. Un Delito Sexual es un problema social que no solo afecta a la víctima como tal, afecta a sus familiares, amigos; y el tabú moralista en nuestro país aún existe por lo que tratando de minimizar las cosas acuden a otros lugares, que a las entidades correspondientes, y por los distintos campos que abarca cada área los procedimiento en un caso de delito sexual no podrían ser aplicados de forma correcta como para una investigación judicial (López H., 2010). Es por ello que la intención de la presente investigación es probar una alternativa que pueda ser utilizada en distintos sitios ya que al ser contrastada con un estándar como es la Técnica de Árbol de Navidad o Christmas Tree constituya parte del primer indicio en la corroboración de un delito sexual siendo una evidencia confiable y muy poco cuestionable al ser presentada ante un juicio.

El estudio del Líquido espermático es de vital importancia y dentro de este se encuentra el rastreo de espermatozoides, lo cual se realiza mediante tinciones que permiten el contraste al momento de su visualización al microscopio, la Técnica de Christmas Tree o Árbol de Navidad para el rastreo de espermatozoides, fue visto por primera vez al microscopio por Van Leeuwenhoek en el año 1678, quien observo espermatozoides células que se encuentra 
exclusivamente en el tracto genital masculino y cuya finalidad es la reproducción. La anatomía del espermatozoide consta de una cabeza, un cuello y una cola que es más larga con relación a al tamaño de la cabeza. Esta tinción es específica para espermatozoides, el material nuclear se tiñe de color rojo o rojo/púrpura, el cuerpo de los espermatozoides se observa de forma ovalada y teñido de rojo con un fondo rosado ligero, el acrosoma del espermatozoide se tiñe de color rojo ligero, la región media y la cola de los espermatozoides se tiñen de color verde o azul verdoso. (Atieza I. y Martínez P. 2010)

La técnica que probaremos será la técnica de Eosina, la cual también conocida como un test de vitalidad o de Williams Pollack, esta es una tinción supra vital, muy utilizada en el laboratorio Clínico dentro del espermatograma para determinar espermatozoides vivos y muertos, debido que en los espermatozoides muertos poseen gran permeabilidad de la membrana, permitiendo teñir su estructuras de un color Rojo / Rosado distinguiéndose cabeza y cola del espermatozoide. (Mellisho E.)

Basándonos en los principios anteriores y como parte objetiva de nuestra investigación a más de comparar la visualización al microscopio de las técnicas aplicadas al rastreo de espermatozoides queremos obtener una alternativa confiable de tinción con resultados exitosos, que se pueda aplicar dentro del marco legal.

\section{Metodologia.}

La investigación es de tipo experimental, comparativa de campo con el que se pudo establecer conclusiones por método inductivo y deductivo, se trabajó con varias muestras en esta investigación transversal, por lo cual trabajamos con toda la población como muestra; Toda la información en la investigación se obtuvo mediante el análisis documental extraído de una fuente secundaria y la aplicación de las Técnicas de Christmas Tree y Eosina para el rastreo de espermatozoides ejecutando los protocolos y procedimientos ya conocidos en el análisis de las diferentes muestras. Usamos los materiales y equipos disponibles en la Universidad Nacional de Chimborazo para el análisis de las muestras, de las cuales se realizó dos placas /frotis de nuestras muestras conocidas para aplicar la tinción de Christmas Tree y la segunda para Eosina, que nos permite documentar mediante fotografías los hallazgos positivos, como se incluyen en los informes periciales.

\section{Protocolo para la obtención de muestra en Soporte Sólido}

Existen muchos casos en los que los fluidos biológicos como el semen se deben retirar de soportes sólidos como son la ropa interior de la víctima o del agresor para posterior estudio de espermatozoides. Para estos casos, debemos recurrir a un procedimiento llamado levantamiento de evidencias en donde recuperamos los fluidos biológicos para estudio, para lo cual utilizamos el siguiente procedimiento:

1. Observar el soporte solido en la luz forense. 
2. Identificar la zona en donde existe fluorescencia para determinar la ubicación del supuesto fluido biológico.

3. La extracción de muestras en superficies solidas se tomará con hisopo (corte longitudinal) y en los demás casos se realizará un corte aprox. $3 \mathrm{~mm}$ ó $5 \mathrm{~mm}$.

4. Agregar en un microtubo con 200ul de buffer de extracción.

5. Agitar con un dispositivo Vortex por 30 minutos a mínima rpm.

6. Centrifugue la muestra 8 minutos a $3.600 \mathrm{rpm}$.

7. Eliminar el sobrenadante con una pipeta.

8. Transferir el sedimento a una placa porta objetos.

9. Fijar la placa.

10. Realizar la tinción “Árbol de Navidad” descrita anteriormente.

\section{Técnica de Christmas Tree}

1. Visualizar en la placa donde se encuentra el frotis y delimitar el frotis con lápiz demográfico.

2. Fijar el frotis a calor seco o exponerlo a la llama directamente.

3. Colocar unas cuantas gotas (que cubra el frotis) de la solución Kernechtrot (rojo nuclear) y dejar durante 20 min. (Reactivo 1).

4. Lavar con agua destilada.

5. Colocar unas cuantas gotas (que cubra el frotis) de la solución picroíndigocarmine y dejar actuar con el tiempo correspondiente a 15 segundos (Reactivo 2)

6. Aclarar el frotis con etanol al $95 \%$ lavando la placa.

7. Dejar secar y montar la placa con permount.

8. Observar en lente $40 \mathrm{X}$

\section{Técnica de Eosina}

1. Visualizar el frotis

2. Fijar el frotis a calor seco o a la llama directamente

3. Colocar unas cuantas gotas de Eosina, de manera que cubra todo el frotis

4. Dejar actuar 1 minuto

5. Lavar con agua destilada

a. Dejar secar y montar con Permount

6. Observar en lente $40 \mathrm{X}$

\section{Resultados.}

Se analizaron un total de 62 muestras en un periodo de 6 meses como se observa en la Tabla 1 , y el número de casos atendidos por mes. Con un total de 107 muestras analizadas, obtuvimos 50 resultados positivos para la presencia de espermatozoides, y 57 negativos para el rastreo de espermatozoides presentados en la Tabla 2. 


\begin{tabular}{|c|c|c|c|}
\hline & \multicolumn{3}{|c|}{ Muestras Sexuales por Mes } \\
\hline Mes & $\begin{array}{l}\text { Número } \\
\text { Casos }\end{array}$ & de & Porcentaje \\
\hline Julio & & 8 & $13 \%$ \\
\hline Agosto & & 11 & $18 \%$ \\
\hline Septiembre & & 9 & $15 \%$ \\
\hline Octubre & & 12 & $19 \%$ \\
\hline Noviembre & & 10 & $16 \%$ \\
\hline Diciembre & & 12 & $19 \%$ \\
\hline
\end{tabular}

$\begin{array}{lllll}\text { Tabla 1: } & \text { Total } & 62 & 100 \% & \begin{array}{l}\text { Número Casos de } \\ \text { Sexuales dados en } \\ \text { Delitos } \\ \text { el Periodo Julio -Diciembre 2016 }\end{array}\end{array}$

Fuente: Datos obtenidos de las muestras Analizadas Elaborado por: Joseline Frías

Al observar las placas al microscopio se documentaron los hallazgos positivos fotográficos en los cuales se evidencian las diferencias de la tinción entre la Técnica de Eosina con la Técnica de Christmas Tree, la Figura A nos muestra la tinción de Christmas Tree, en la cual observamos la diferenciación celular esperada y descrita por varios autores años atrás en la cual se observara la cabeza, acrosoma de color rojo/ rosado y la cola de color verde, lo que permite el reconocimiento acertado de las células espermáticas y sus estructuras, así es posible reconocer solo cabezas o solo la cola del espermatozoide, lo cual indicaría la presencia de los mismos reportándose como positivo para cabezas o colas, esta técnica aplicada al rastreo de espermatozoides en caso de delitos sexuales, usada y estandarizada dentro del marco judicial en varios países, como en Colombia -Bogotá en el centro de Biología Forense de la Dirección Regional de Bogotá tras trabajar con gran cantidad de casos adjudican la efectividad de visualización de esta técnica calificándola como un éxito en el rastreo de espermatozoides, a la propiedad química de sus colorantes, en esto coinciden los peritos Martínez y Vallejo que de igual manera describen la calidad de visualización de la Tinción de Christmas Tree en el rastreo de espermatozoides. Para corroborar lo dicho, presentamos las figuras: 1A) Observamos Hisopado Vaginal, donde se aprecia al 
espermatozoide con la tinción de Christmas Tree, Cabeza color Rojo, Acrosoma Rosado, cola verde; cerca de una célula epitelial. 1B) Es una muestra recuperada de un soporte sólido, Hisopado de Interior zona Mariposa, donde observamos gran cantidad de espermatozoides concentrado donde se aprecia la tinción y su especificidad.

\begin{tabular}{r|rr}
\hline \multicolumn{3}{c}{ Número de Análisis Realizados } \\
\hline $\begin{array}{r}\text { Resultado de } \\
\text { Análisis }\end{array}$ & Cantidad & Porcentaje \\
Positivo & 50 & $47 \%$ \\
Negativo & 57 & $53 \%$ \\
Total & 107 & $100 \%$ \\
\hline
\end{tabular}

Tabla 2: Número de Análisis Positivos (Presencia) y Negativos (Ausencia) para Espermatozoides dados en el Periodo Julio -Diciembre 2016

Fuente: Datos obtenidos de las muestras Analizadas

Elaborado por: Joseline Frías

En la Figura 2 observamos la tinción con Eosina , una tinción no antes probada en el rastreo de espermatozoides, aunque existen descripciones de rastreos hechos con otras técnicas de tinción diferentes a la de Christmas Tree como la de Eosina/ Nigrosina, Papa Nicolau, Azul de Metileno, pero ninguna de estas echa como un estudio específico del rastreo y mucho menos comparada al estándar que se maneja dentro de la investigación de un delito sexual, es por ello que hasta ahora no se recomienda ninguna de estas en el rastreo de Espermatozoides.

La Técnica de Eosina presenta una coloración Rojo /rosada de la célula espermática, obteniendo una excelente infiltración del colorante en la estructura celular, dando muy buen contraste para el reconocimiento de forma en el rastreo, diferenciando la cabeza de la cola, la cabeza de rosado y la cola de rojo, permitiendo una buena visualización, garantizando confiabilidad en el rastreo para la validación de resultados; presentamos la Figura 2A) Hisopado Vaginal, donde se observa al espermatozoide con la tinción de Eosina, se diferencia de forma clara la Cabeza de la cola y una célula epitelial. 2B) Muestra de recuperada de un soporte sólido, interior zona mariposa, observamos la concentración de espermatozoides donde observamos la tinción en las células espermáticas.

Figura $\mathbf{N}^{\circ}$ 1: Tinción de Christmas Tree 


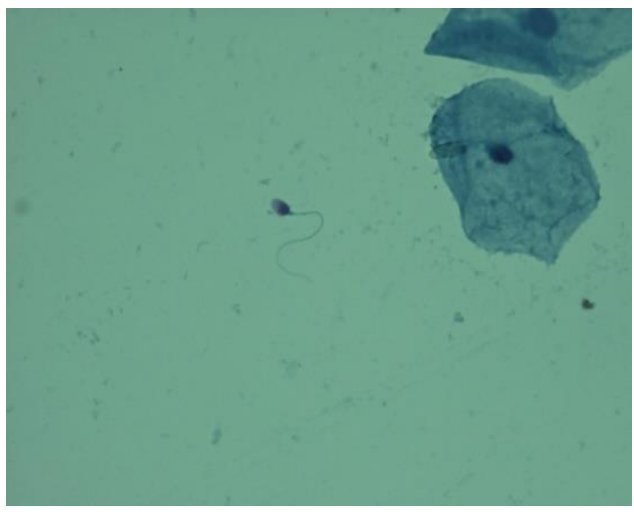

Fig. 1A) Hisopado Vaginal

Fuente: Laboratorio de la UNACH

Figura $\mathbf{N}^{\circ}$ 2: Tinción con Eosina

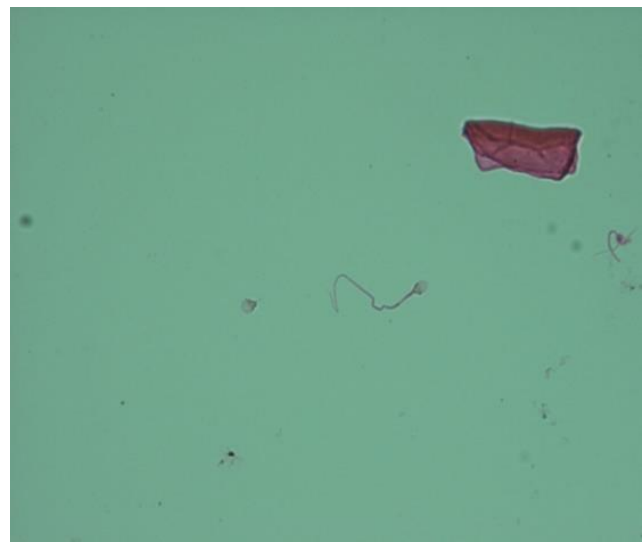

Fig. 2A) Hisopado Vaginal

Fuente: Laboratorio de la UNACH

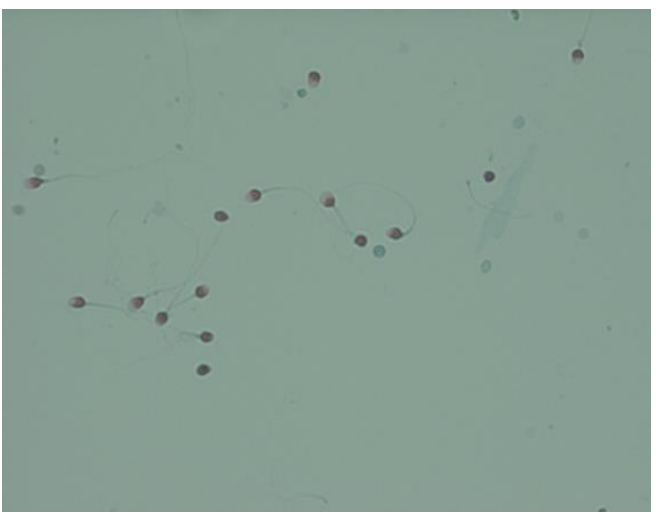

Fig. 1B) Hisopado Interior zona Mariposa

Fuente: Laboratorio de la UNACH

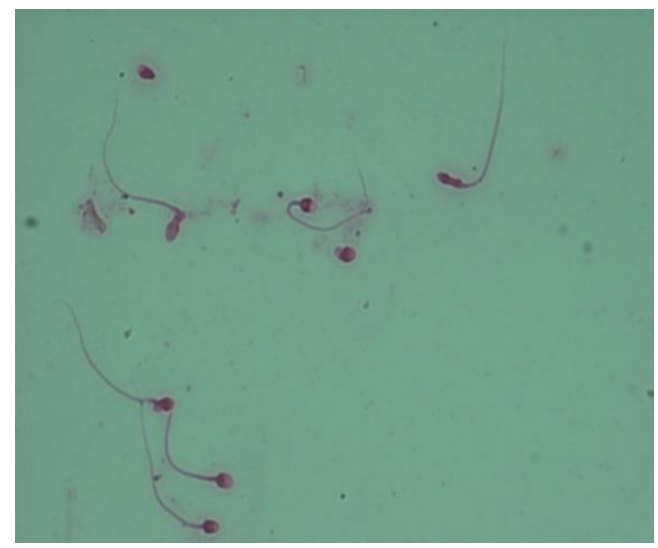

Fig. 1B) Hisopado Interior zona Mariposa Fuente: Laboratorio de la UNACH

Al comparar las dos tinciones observadas hallamos la mayor diferencia de estas, que radica en la especificidad del contraste dado por los colorantes, en la técnica de Christmas Tree como describimos en la observación, existe especificidad en las estructuras espermáticas celulares, mientras que en la técnica de Eosina esta cualidad está ausente, esto se debe en primera a la variedad de colorantes usados en cada técnica que interfiere de manera directa en la complejidad y costos de las mismas, pero que en calidad de visualización para identificar a espermatozoides no interfiere de forma radical siendo la técnica de Eosina una alternativa exitosa en el rastreo de espermatozoides, aplicada en casos de delito sexual lo cual podría permitirse como evidencia en un juicio. 


\section{Conclusiones}

- Probamos una nueva alternativa para el rastreo de espermatozoides, en los casos de delitos sexuales, con una técnica más sencilla, fácil de aplicar y más accesible para las casas de salud

- Al analizar el resultado obtenidos del rastreo de espermatozoides realizados mediante la técnica de Christmas Tree y Eosina obtuvimos datos relevantes con respecto a la efectividad de la observación de cada una de las técnicas.

- Establecimos las ventajas y desventajas en el uso de ambas técnicas tanto de Christmas Tree como de la Eosina en el rastreo de espermatozoides.

\section{Referencias bibliográficas}

Atienza I, Martínez P. Identificación de vestigios de semen. Delgado Bueno S, director. Patología y Biología Forense. Tratado de Medicina Legal y Ciencias.

Forenses (T. III). Editorial Bosch; 2010; p. 993---1013.

Ecuador Inmediado. Fiscalía completo la apertura de 8 centros Forenses en Ecuador.

Ecuador: Ecuador Inmnediato.com. Edición \#4135. 17 de Febrero del 2015; [30 de

$\begin{array}{llll}\text { Noviembre } & \text { del 2016]. } & \text { Disponible }\end{array}$ http://www.ecuadorinmediato.com/index.php?module=Noticias\&func =news_user_view\&id=2818776472

López H. Biología Forense en la Escena del Crimen.[SlideShare].Julio 2010;[05 de Diciembre del 2016]. Disponible en : http://es.slideshare.net/josacama biologiaforense- 4664088

Mellisho E. Manual de Laboratorio de Reproducción.2010;[08 de Diciembre del 2016]. Disponible en: http://tarwi.lamolina.edu.pe/ emellisho/ Reproduccion_archivos/Practica\%204-eval-semen.pdf

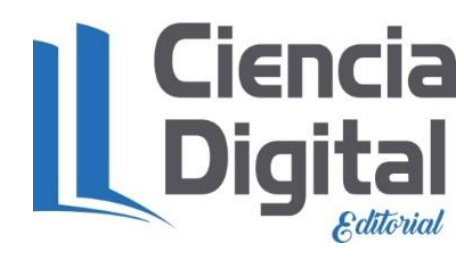


Para citar el artículo indexado.

Frías J., Cáceres V., Monge A. \& Lescano P. (2019) Investigación científica forense mediante técnicas de coloración en casos de delito sexual. Revista electrónica Ciencia Digital 3(1.1), 9098. Recuperado desde:

http://cienciadigital.org/revistacienciadigital2/index.php/CienciaDigital/article/view/361/779

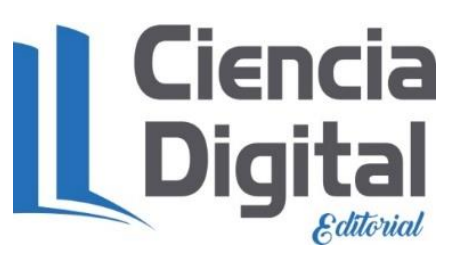

El artículo que se publica es de exclusiva responsabilidad de los autores y no necesariamente reflejan el pensamiento de la Revista Ciencia Digital.

El articulo queda en propiedad de la revista y, por tanto, su publicación parcial y/o total en otro medio tiene que ser autorizado por el director de la Revista Ciencia Digital.
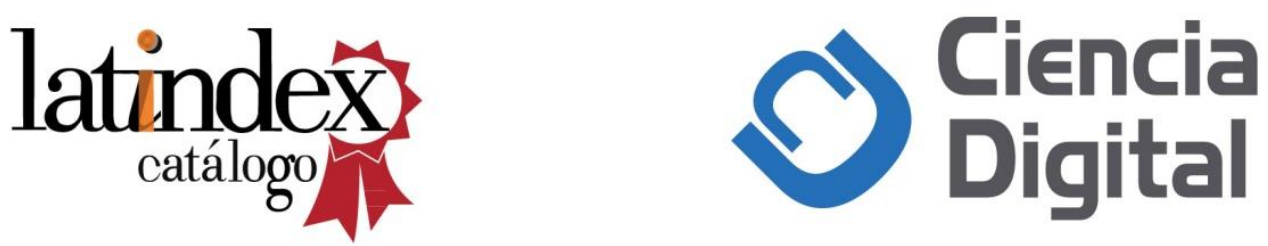